\title{
Viability of the "Technology Acceptance Model" in Multimedia Learning Environments: A Comparative Study
}

\author{
Raafat George Saadé, Fassil Nebebe, and Weiwei Tan \\ John Molson School of Business, Concordia University \\ Montreal, Quebec, Canada
}

\author{
rsinfo@sympatico.ca fnebebe@imsb.concordia.ca \\ ww tan@jimsb.concordia.ca
}

\begin{abstract}
In recent years, more and more higher education institutions have interests of integrating internetbased technologies in the classroom as part of the learning environment. Compared to studies on other information technologies, users' behavior towards this type of systems, however, has not been assessed and understood thoroughly. In order to get more experience about human behaviors on multimedia learning environment, we conducted a comparative study consisting of 362 students, which is almost three times the sample size of the previous study, participating to test the theoretical model. Results suggest that TAM is a solid theoretical model where its validity can extend to the multimedia and e-learning context. The study provides a more intensive view of the multimedia learning system users and is an important step towards a better understanding of the user behavior on the system and a multimedia acceptance model.
\end{abstract}

Keywords: Multimedia Learning System, TAM, eLearning, Information Technology

\section{Introduction}

It is evident today that the use of Internet technologies has significant impacts on every aspect of our lives. In the context of education industry more and more higher education institutions have come to realize the potential impact of using the Internet in the classroom as part of the learning environment. An overview of e-learning and how it is being implemented using content management systems is provided by Cohen and Nycz (2006). Despite the many challenges yet to be overcome, the advantages of Internet-based learning have been widely recognized. Some of these major advantages include flexibility and broader accessibility (Lee, Cheung, \& Chen, 2005), improved students' performance (Alavi, 1994), reflective evaluation of the learning experience (Hiltz, 1995), and higher computer self-efficacy (Piccoli, Ahmad, \& Ives, 2001). Academic insti-

Material published as part of this publication, either on-line or in print, is copyrighted by the Informing Science Institute. Permission to make digital or paper copy of part or all of these works for personal or classroom use is granted without fee provided that the copies are not made or distributed for profit or commercial advantage AND that copies 1) bear this notice in full and 2) give the full citation on the first page. It is permissible to abstract these works so long as credit is given. To copy in all other cases or to republish or to post on a server or to redistribute to lists requires specific permission and payment of a fee. Contact Publisher@InformingScience.org to request redistribution permission. tutions also benefit in terms of cost reductions and increasing revenues (Saadé and Bahli, 2005).

The success of internet-based technologies usage for learning is primarily due to its potential to integrate various types of media (such as sound, video, graphics, text, etc.) and delivered in various forms (such as collaboration, interactive, simulation, etc.). Therefore the use of multimedia learning system (MMLS) is 
defined in this article as a system-mediated learning environment allowing users to interact with various media types and forms, and providing access to a wide range of resources (Cochrance, 2005; Gonzalez, 2000; Wilson, 1996). Many universities are now beginning to develop and deliver their programs through MMLSs. At the same time, studies done on MMLSs have mainly focused on determining how to use internet-based tools/objects to support instruction, to assess user satisfaction (Wang, 2003), and to characterize the internet-based learning student (Kim \& Schniederjans, 2004; Lu, Yu, \& Liu, 2003). Some studies have only recently examined the development and design of learning objects and their effectiveness in demonstrating that learning did occur (Krauss \& Ally, 2005; Salas \& Ellis, 2006).

However, student acceptance behavior towards MMLSs has only been assessed in few studies. In general, like any information systems, user acceptance and usage are important primary measures of system success (DeLone \& McLean, 1992). Without consideration on student involvement and participation, even the best developed system cannot be successful (Catchpole, 1993). Similarly, a successful MLS should be widely adopted with active participation from students.

This paper constitutes a continuation of the research stream for the development of a multimedia acceptance model for internet-based learning. In this paper we report the results of a modest contribution where the technology acceptance model (TAM) was used to re-assess student satisfaction on a multimedia tool used by Saade and Galloway (2005). Therefore this study is comparative with three times the sample size of the previous one. The primary objective is to validate the TAM and establish it as a viable baseline to its extension towards a multimedia acceptance model (MAM).

\section{Research Model and Hypotheses}

In an attempt to understand determinants of information technology end-user's behaviors toward information technologies, various theoretical models have been developed (the theory of reasoned action, the technology acceptance model, the theory of planned behavior, the motivational model, self-efficacy theory and the big five). This study is based on the technology acceptance model (TAM) proposed by Davis (1989) and which has been extended and applied to different information technologies, work environments, and end-users. In the TAM, Davis proposes that the influence of other variables on technology acceptance is mediated by two individual beliefs: perceived ease of use (PEU) and perceived usefulness (PU). In our work, PEU refers to the degree to which an individual believes that using a MMLS would be free of cognitive effort, whereas PU is defined as the degree to which an individual believes that using a MMLS would enhance his or her performance in the course. TAM suggests that the actual use of the system is determined by the users' behavioral intentions (INT) to use the system, which is in turn jointly determined by the users' attitudes towards using the system and their perceived usefulness of the system (Davis, Bagozzi, \& Warshaw, 1989). Note that all symbols and notations are consistent with those in Saade and Galloway (2005) article for ease of comparison.

In prior Internet technologies related behavior studies (see Table 1), many researchers dropped attitude from the structural model of TAM, because of its weak strength in mediating beliefs' impact on behavioral intention to use (Davis et al., 1989) the target system. Attitude towards the system has been identified as an essential determinant to behavioral intention, as described in the theory of reasoned action. After several studies, Davis et al. dropped the attitude construct. Their studies however, dealt with the use of desktop software such as word processing and spreadsheet and were very long time ago. In this study, we keep the attitude construct to validate its importance in the original TAM as it relates to our multimedia context. 


\begin{tabular}{|c|c|c|c|c|c|c|c|}
\hline Authors & Research subjects & $\begin{array}{l}\text { PEU } \\
\rightarrow \text { PU }\end{array}$ & $\underset{\rightarrow \text { INT }}{\text { PEU }}$ & $\underset{\rightarrow \text { INT }}{\text { PU }}$ & $\underset{\rightarrow \text { ATT }}{\text { PEU }}$ & $\begin{array}{l}\text { PU } \rightarrow \\
\text { ATT }\end{array}$ & $\mathrm{ATT} \rightarrow \mathrm{INT}$ \\
\hline $\begin{array}{l}\text { Saadé \& Bahli } \\
\text { (2005) }\end{array}$ & 102 undergraduates & 0.28 & 0.16 & 0.43 & & & \\
\hline Lee et al. (2005) & 544 students & 0.51 & & 0.19 & n.s & 0.39 & 0.35 \\
\hline Hsu \& Lu (2004) & $\begin{array}{l}233 \text { on-line game } \\
\text { users }\end{array}$ & 0.23 & & n.s & 0.57 & 0.14 & 0.99 \\
\hline Heijden (2003) & $\begin{array}{l}828 \text { website brows- } \\
\text { ers }\end{array}$ & 0.49 & & 0.18 & 0.23 & 0.17 & 0.5 \\
\hline $\begin{array}{l}\text { Yi \& Hwang } \\
\text { (2003) }\end{array}$ & 109 students & 0.02 & 0.22 & 0.46 & & & \\
\hline $\begin{array}{l}\text { Moon \& Kim } \\
\text { (2001) }\end{array}$ & 152 students & 0.31 & & 0.269 & 0.23 & 0.33 & 0.29 \\
\hline \multirow[t]{2}{*}{$\begin{array}{l}\text { Agarwal \& Kara- } \\
\text { hanna (2000) }\end{array}$} & $\begin{array}{l}288 \text { college students } \\
\text { (Test } 1)\end{array}$ & 0.20 & 0.307 & 0.475 & & & \\
\hline & (Test 2) & 0.20 & 0.21 & 0.37 & & & \\
\hline \multirow{3}{*}{$\begin{array}{l}\text { Teo, Lim, \& Laia } \\
\text { (1999) }\end{array}$} & $\begin{array}{l}1370 \text { Internet users } \\
\text { (Frequency) }\end{array}$ & \multirow{3}{*}{0.35} & 0.19 & 0.19 & & & \\
\hline & (Daily of usage) & & 0.03 & 0.16 & & & \\
\hline & (Diversity of usage) & & 0.11 & 0.21 & & & \\
\hline \multicolumn{8}{|c|}{$\begin{array}{l}\mathrm{PU}=\text { Perceived Usefulness, PEU=Perceived Ease of Use, INT=Behavioral Intention, ATT }=\text { Attitude } \\
\text { towards system }\end{array}$} \\
\hline \multicolumn{8}{|c|}{ All values are significant with $p<0.05$} \\
\hline
\end{tabular}

In prior TAM studies, the mainstream of researchers chose workers in a business environment as their study samples and context (Legris, Ingham, \& Collerette, 2003). Subjects in their working environments are required to use (mandatory setting) target technologies because of their daily work needs or business demands. In contrast, the present study entailed the voluntary use of the MMLS. Some students might not believe that using the MMLS or any other internet-based tool is the most effective way to learn; consequently students may not even use the tool at all. Drawing upon the literature and based on the present research context, we hypothesize the following:

H1: Perceived usefulness will have a strong positive effect on behavioral intention.

H2: Perceived ease of use has a positive effect on perceived usefulness on the WLS

H3: Perceived usefulness has a significant positive effect on attitude.

H4: Perceived ease of use has a significant positive effect on attitude.

H5: Attitude has a significant positive effect on behavioral intention.

The theoretical model used here is presented in Figure 1 (which represents a causal relationship schema). In this figure, the boxes represent the constructs which were measured by a set of item, the arrows represent the hypotheses 1 to 5 as mentioned above and the ' + ' sign besides the hy- 


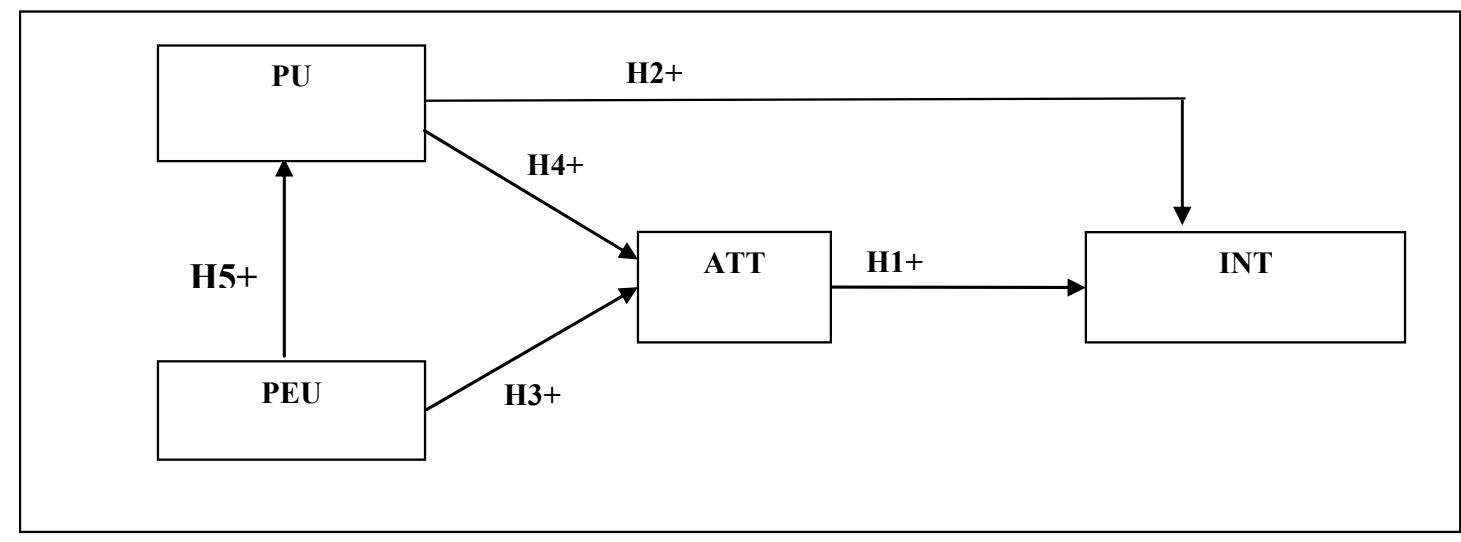

Figure 1: The Proposed Research Model (Davis, 1989)

potheses indicates the expected influence to be positive. Figure 1 captures the relationship between beliefs and how these beliefs are the primary determinants of attitude towards MMLS use. The PU and attitude jointly influence the behavioral intention to use MMLSs.

\section{Research Methodology}

\section{Operationalization of Constructs}

The same methodology as that of Saade and Galloway (2005) was followed. Data were collected via a 13-item questionnaire administered at the end of the course. A five-point Likert-type scale with anchors from "Strongly agree" to "Strongly disagree" was used.

The students who completed the questionnaires did so voluntarily with no reimbursement for their participation. Their use of the MMLS was motivated by the desire to practice ERD problem solving with the perception of better performance on this part of the examination. The students who filled out the questionnaire were taking a 300 level core management information systems course at Concordia University in Montreal, Canada.

This study included samples from three successive semesters with students taking the same course delivered by the same professor with the same characteristics and delivery design. The collection of these questionnaires yielded 362 usable data responses. Another dataset used in Saade and Galloway study (2005) is cited for comparison. A structural equation modeling (SEM) approach was followed for the analysis of data using PLS graph software.

\section{Target Technology}

The same MMLS from Saade and Galloway (2005) was used in this study. The MMLS is a webbased learning tool developed in-house using Macromedia Flash. The purpose of the MMLS is to provide students with a multimedia environment to learn the concepts of entity relationship diagrams (ERDs) as part of an undergraduate management information systems course and practice making ERD's in an interactive medium.

The user is given a whiteboard for workspace and access to ERD symbols. Using the MMLS the student can drag and drop ERD symbols onto the workspace. He/she must place the correct ER symbols in the correct relationships. In this fashion the MMLS is similar to a puzzle game, where the ERD symbols are the pieces. The entity specifications used in each problem are supplied by a case given to the user at the beginning of each session. There is only one fully correct answer to each case but there are multiple ways of solving each case depending on the case. 
The MMLS is accessible via the web using any internet browser. The student accesses the MMLS by logging into the course folder. The student is given the option to view an animated presentation that explains ERD concepts. In the practicing problem area of the MMLS, the student is presented with a case that describes the business situation and the database needs. The student then drags one symbol at a time from the object repository panel and drops it in the workspace. This panel is blank at the beginning of the problem. Movement of symbols is permitted at all times within the workspace. Details to the MMLS are presented in the Saade and Galloway (2005) article.

\section{Data Analysis of Results}

The Partial Least Square (PLS) approach to multiple indicator structural equation analysis was used to analyze both (1) the measurement model and (2) structural model. PLS is a latent structural equation modeling technique that utilizes a component-based approach. The assessment of the measurement model implied that individual item loadings and internal consistency reliabilities were examined as a test of reliability. Discriminant validity verifies that items should load higher on their own construct than on the others in the model, and the average variance shared between the constructs and their measures should be greater than the variances shared between the constructs themselves. The structural model and hypotheses were tested by examining the path coefficients and their significance. The PLS approach can be used for theory confirmation and to suggest where relationships might exist. For prediction, the PLS approach is more suitable than others, such as LISREL and EQS, because it assumed that all the measured variance in the study were to be explained.

The measurement model in PLS is assessed in terms of item loadings and internal consistency, as well as the convergent and discriminant validity. Reliabilities of individual items are considered adequate, when items' loading on their respective constructs is higher than 0.5 (Rivard, 1988). A composite reliability of 0.70 or greater is considered acceptable (Fornell \& Larcker, 1981). Establishing discriminant validity in PLS also requires an appropriate AVE (Average Variance Extracted) analysis. It should be greater than 0.50 and in an AVE analysis, the square root of every AVE (there is one for each latent construct) should be much larger than any correlation among any pair of latent constructs. Also, the discriminant validity of the measures (the degree to which items differentiate among constructs or measure distinct concepts) was assessed by examining the correlations of the latent variable scores with the measurement items. Items should load more strongly on their own theoretically assigned constructs than on other constructs in the model (Gefen \& Straub, 2005).

The structural model in PLS is assessed by examining the path coefficients (standardized betas). $\mathrm{T}$ statistics are also calculated to assess the significance of these path coefficients. In addition, $R^{2}$ is used as an indicator of the overall predictive strength of the model.

\begin{tabular}{|l|c|c|c|c|c|c|c|}
\hline \multirow{2}{*}{ Variables } & \multirow{2}{*}{$\begin{array}{c}\text { No. of } \\
\text { items }\end{array}$} & \multicolumn{2}{c|}{ Rho } & \multicolumn{2}{c|}{ Mean } & \multicolumn{2}{c|}{ SD } \\
\cline { 3 - 8 } & & 2005 & 2006 & 2005 & 2006 & 2005 & 2006 \\
\hline PU & 4 & 0.95 & 0.95 & 3.5 & 3.5 & 0.95 & 0.88 \\
\hline PEU & 4 & 0.96 & 0.94 & 3.5 & 3.7 & 1.09 & 0.96 \\
\hline ATT & 3 & 0.90 & 0.93 & 3.5 & 3.7 & 0.93 & 0.87 \\
\hline INT & 2 & 0.92 & 0.93 & 4.0 & 3.6 & 1.04 & 0.88 \\
\hline
\end{tabular}


Table 2 displays the descriptive statistics showing the present study results (2006) as well as the Saade and Galloway study (2005). The results show that the values of the composite reliabilities of all constructs are above the acceptable limit of 0.7 .

The PLS confirmatory factor analysis was performed. Results have shown that all other loadings are higher than the suggested 0.50 and load significantly higher on their own respective constructs than on other constructs in the model. The correlations of latent variables presented in table 3 shows satisfactory convergent and discriminant validity of measures. Cells on the diagonal are the results of the AVE square roots and the off diagonals are the results of the squared correlations. AVEs of all constructs are higher than 0.5 and larger than off-diagonal elements, the correlations among constructs. Thus, the results indicate that discriminant and convergent validity of the measures are reasonable.

\begin{tabular}{|c|c|c|c|c|c|c|c|c|}
\hline \multicolumn{7}{|c|}{ Table 3: Correlation of Latent Variables } \\
\hline Variables & \multicolumn{2}{|c|}{ PU } & \multicolumn{2}{c|}{ PEU } & \multicolumn{2}{c|}{ ATT } & \multicolumn{2}{c|}{ INT } \\
\hline & 2005 & 2006 & 2005 & 2006 & 2005 & 2006 & 2005 & 2006 \\
\hline PU & $\mathbf{0 . 8 6}$ & $\mathbf{0 . 9 0}$ & \multicolumn{3}{|c|}{} & & & \\
\hline PEU & 0.49 & 0.51 & $\mathbf{0 . 8 3}$ & $\mathbf{0 . 8 9}$ & & & \multicolumn{2}{|c|}{} \\
\hline ATT & 0.43 & 0.62 & 0.25 & 0.47 & $\mathbf{0 . 9 5}$ & $\mathbf{0 . 9 0}$ & \multicolumn{2}{|c|}{} \\
\hline INT & 0.43 & 0.45 & 0.37 & 0.27 & 0.54 & 0.60 & $\mathbf{0 . 9 5}$ & $\mathbf{0 . 9 3}$ \\
\hline
\end{tabular}

Next, the path coefficients from the PLS analysis are presented in Figure 2. A positive and strong relationship between PEU and PU was found (path=0.510). The link between PU and ATT was significant (path=0.518), and the link between PU and INT was not significant (path=0.122), indicative of full mediation. PEU has a significant impact on ATT (path=0.205). Consistent with our hypotheses, ATT demonstrated a significant impact on INT (path=0.526). Approximately $37.1 \%$ of the variance in INT and more than $40 \%$ of the variance in ATT was explained by beliefs. In addition, $26.1 \%$ of the variance in PU was explained by PEU.

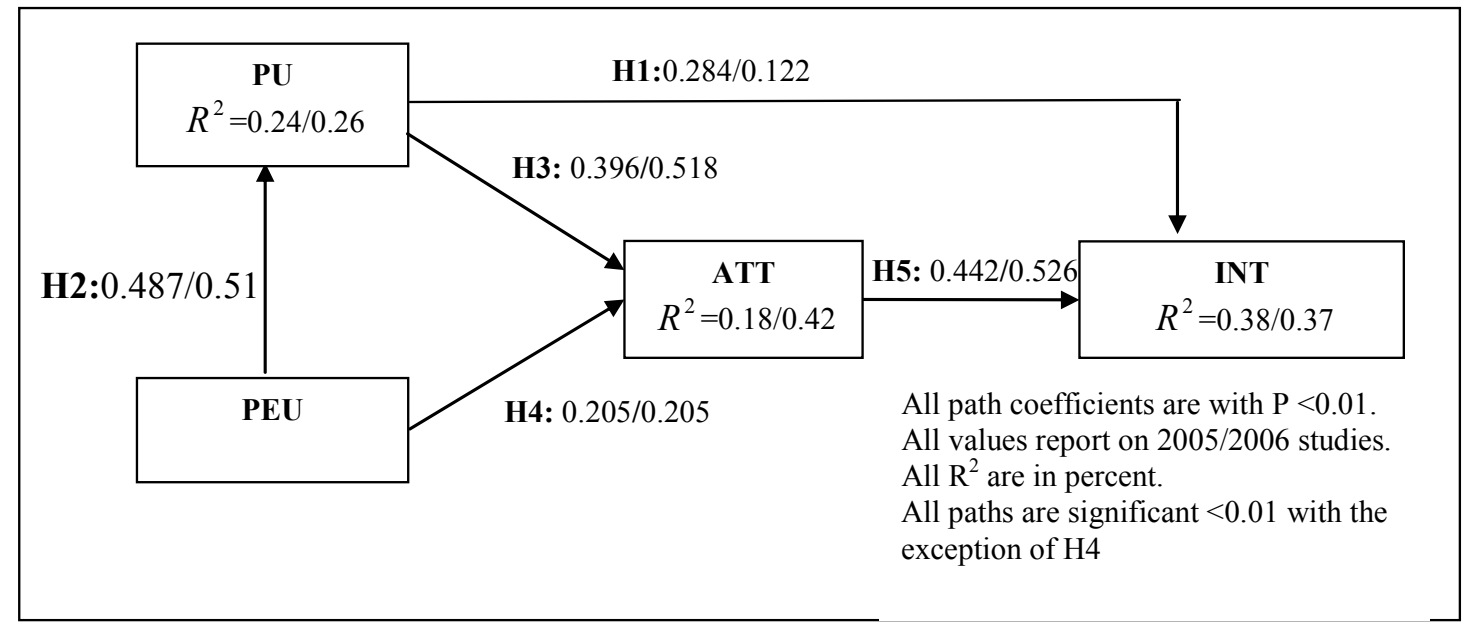

Figure 2: PLS Research Model Results

The model parameters for the two research models are compared in Table 4. This table presents the strength of the relationship between two constructs (identified in column 1), the variance explained $\mathrm{R}^{2}$, and whether the hypothesis was supported or not, for the two studies, the one done in 
2005 and the other in 2006. The strength of the relationship between two constructs represents the path coefficient and support was evaluated over three variables: $\mathrm{S}=$ strong support; $\mathrm{M}=$ moderate support and $\mathrm{N}=$ no support.

Both studies are in agreement with the hypotheses posed by the research model with the slight exception of the first hypothesis which is marginally supported by the previous study and not supported by the present one. In either case, this hypothesis is weak and therefore questionable. In terms of strength of the hypotheses as indicated by the path coefficients of PU-ATT and ATTINT, attitudes are of primary importance in both cases. The relationship appears to be even stronger in the later study which exhibits less internal variability probably due to the size of the data involved. Furthermore, R-squared which is indicative of the explained variance is more than doubled in this study. This further reinforces the significant role of attitudes as a mediating variable in the use of multimedia in the learning context.

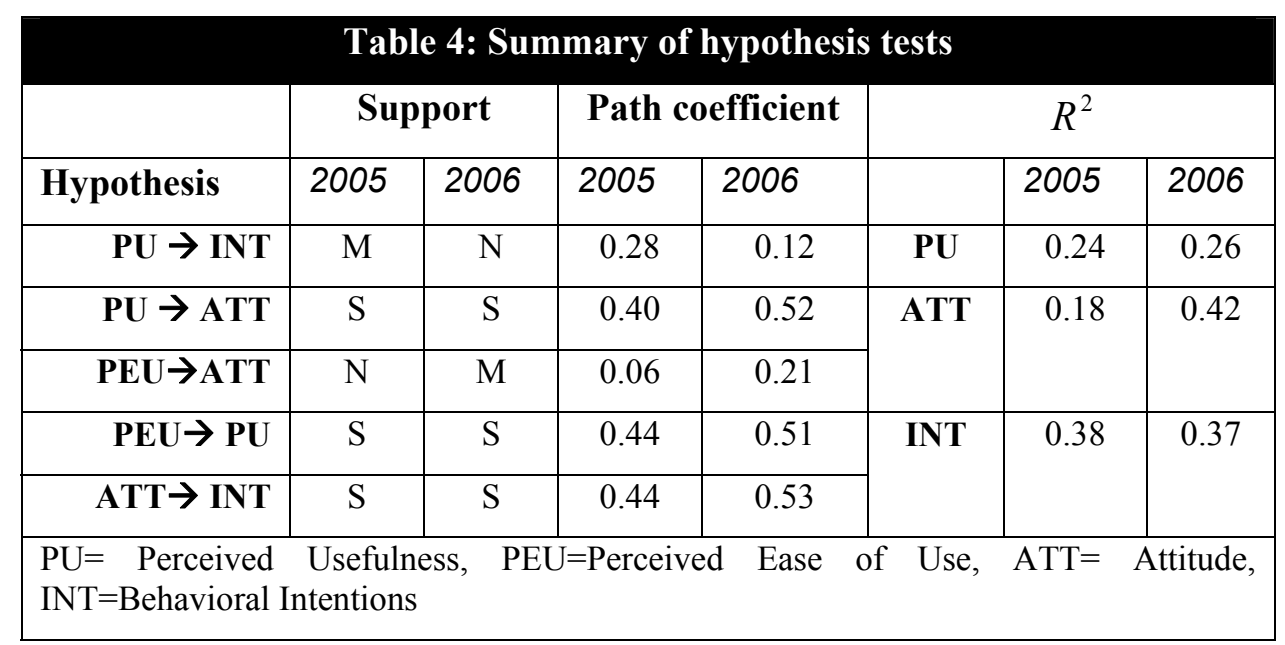

\section{Discussion and Conclusions}

Multimedia learning systems are a subset of e-learning technologies which encompasses many dimensions. In general, e-learning technologies, as reported and used today, lack proper evaluation in terms of development, design, assessment and standards. Achieving a standard for elearning activities for example entails issues such as reusability, and interoperability of content (Varlamis \& Apotolakis, 2006). It is important to emphasize that research in e-learning with all of its subsets (different objects) should include concepts of development, design, assessment and standards.

With respect to the present research work and consistent with the original formulation of the technology acceptance model, we considered the validation of the TAM, including the attitude construct, as an assessment of student satisfaction of MMLS. The measurement model was confirmed with adequate convergent and discriminant validity. In the structural model, all path coefficients were found statistically significant and strong, except for the relationships between PU and BI and PEU and ATT. The results showed that PU has a significant impact on student attitude towards using MMLS. Attitude is confirmed to play an essential role of affecting behavioral intention to use MMLS.

The study is one of the emerging attempts to investigate empirically student acceptance of multimedia learning environments. Additionally, it continues with the line of research to validate the TAM in the MMLS context and builds on a similar study conducted by Saade and Galloway (2005). The use of student sample to measure an application designed for learning make an ap- 
propriate fit between target technology and the study context. As previously reported and discussed, the findings of this research must be considered in light of its limitations. First, the specific use of the MMLS to practice certain study content would limit the user's value of the system. The student's value of the system is largely dependent on the importance individual students place on the task in preparing for their finals. Second, because of its specificity, caution must be taken in generalizing and applying the results to other technologies. What this study brings forward is the validation of the TAM in the context of multimedia usage for learning, hence the Multimedia Acceptance Model, MAM.

The findings validate the TAM as basis for this new model and support the value of attitude toward MMLS in student acceptance. From a practical perspective, this study contributes a theorybased empirical test to future MMLS development. Schools can use the findings to understand the extent at which students are satisfied with a multimedia tool for learning and adjust their instructional strategies accordingly.

\section{References}

Agarwal, R., \& Karahanna, E. (2000). Time flies when you're having fun: Cognitive absorption and beliefs about information technology usage. MIS Quarterly, 24(4), 665.

Alavi, M. (1994). Computer-mediated collaborative learning: An empirical evaluation. MIS Quarterly, $18(2), 159-174$.

Catchpole, M. J. (1993). Interactive media: the bridge between distance and classroom education. In T. Nunan (Ed.), Distance education futures (pp. 37-56). Adelaide: University of South Australia Press.

Cochrance, T. (2005). Interactive quicktime: Developing and evaluating multimedia learning objects to enhance both face-to-face and distance e-learning environments. Interdisciplinary Journal of Knowledge and Learning Objects, 1, 33-54. Available at http://ijklo.org/Volume1/v1p033-054Cochrane.pdf

Cohen, E. B., \& Nycz, M. (2005). Learning objects and e-learning: An informing science perspective. Interdisciplinary Journal of Knowledge and Learning Objects, 2, 23-34. Available at http://ijklo.org/Volume2/v2p023-034Cohen32.pdf

Davis, F. D. (1989). Perceived usefulness, perceived ease of use, and user acceptance of information technology. MIS Quarterly, 13(3), 319.

Davis, F. D., Bagozzi, R. P., \& Warshaw, P. R. (1989). User acceptance of computer technology: A comparison of two theoretical models. Management Science, 35(8), 982.

DeLone, W. H., \& McLean, E. R. (1992). Information system success: The quest for the dependent variable. Information Systems Research, 3(1), 60-95.

Fornell, C., \& Larcker, D. F. (1981). Evaluating structural equations models with unobservable variables and measurement error. Journal of Marketing Research, 18(1), 39-50.

Gefen, D., \& Straub, D. (2005). A practical guide to factorial validity using PLS-Graph: Tutorial and annotated example. Communications of the Association for Information Systems, 16, 91-109.

Gonzalez, R. (2000). Disciplining multimedia. IEEE Multimedia, 7, 72-78.

Heijden, H. V. D. (2003). Factors influencing the usage of websites: The case of a generic portal in The Netherlands. Information \& Management, 40(6), 541-549.

Hiltz, S. R. (1995). Teaching in a virtual classroom. International Journal of Educational Telecommunications, $1(2), 185$.

Hsu, C.-L., \& Lu, H.-P. (2004). Why do people play on-line games? An extended TAM with social influences and flow experience. Information \& Management, 41(7), 853-868.

Kim, E. B., \& Schniederjans, M. J. (2004). The Role of Personality in Web-based Distance Education Courses. Communications of ACM, 47(3), 95. 
Krauss, F., \& Ally, M. (2005). A study of the design and evaluation of a learning object and implications for content development, Interdisciplinary Journal of Knowledge and Learning Objects, 1, pp.1-22. Available at http://ijklo.org/Volume1/v1p001-022Krauss.pdf

Lee, M. K. O., Cheung, C. M. K., \& Chen, Z. (2005). Acceptance of Internet-based learning medium: The role of extrinsic and intrinsic motivation. Information \& Management, 42(8), 1095-1104

Legris, P., Ingham, J., \& Collerette, P. (2003). Why do people use information technology? A critical review of the technology acceptance model. Information \& Management, 40, 191-204.

Lu, J., Yu, C.-S., \& Liu, C. (2003). Learning style, learning patterns, and learning performance in a WebCT-based MIS course. Information \& Management, 40, 497-507.

Moon, J.-W., \& Kim, Y.-G. (2001). Extending the TAM for a World-Wide-Web context. Information \& Management, 38 (4), 217-230.

Piccoli, G., Ahmad, R., \& Ives, B. (2001). Web-based virtual learning environments: A research framework and a preliminary assessment of effectiveness in basic IT skills training. MIS Quarterly, 25(4), 401.

Rivard, S. H. (1988). Factors for success for end-user computing. Communications of ACM, 31(5), 552561.

Saadé, R., \& Bahli, B. (2005). The impact of cognitive absorption on perceived usefulness and perceived ease of use in on-line learning: An extension of the technology acceptance model. Information \& Management, 42(2), 261-386.

Saadé, R., \& Galloway, I. (2005). Understanding intention to use multimedia information systems for learning. Issues in Informing Science and Information Technology, 2, 287-296. Available at http://2005papers.iisit.org/I23f15Saad.pdf

Salas, de K. \& Ellis, L. (2006). The development and implementation of leaning objects in a higher education setting, Interdisciplinary Journal of Knowledge and Learning Objects, 2, 1-22. Available at http://ijklo.org/Volume2/v2p001-022deSalas.pdf

Teo, T. S. H., Lim, V. K. G., \& Laia, R. Y. C. (1999). Intrinsic and extrinsic motivation in Internet usage. Omega, 27(1), 25-37.

Varlamis, I. \& Apostolakis, I. (2006). The present and future of standards for e-learning technologies, Interdisciplinary Journal of Knowledge and Learning Objects, 2, 59-76. Available at http://ijklo.org/Volume2/v2p059-076Varlamis.pdf

Wang, Y.-S. (2003). Assessment of learner satisfaction with asynchronous electronic learning systems. Information \& Management, 41(1), 75-86.

Wilson, B. G. (1996). Constructivist learning environments: Case studies in instructional design. Englewood Cliffs, NJ: Educational Technology Publications.

Yi, M. Y., \& Hwang, Y. (2003). Predicting the use of web-based information systems: Self-efficacy, enjoyment, learning goal orientation, and the technology acceptance model. International Journal of Human-Computer Studies, 59, 431-449. 


\section{Biographies}

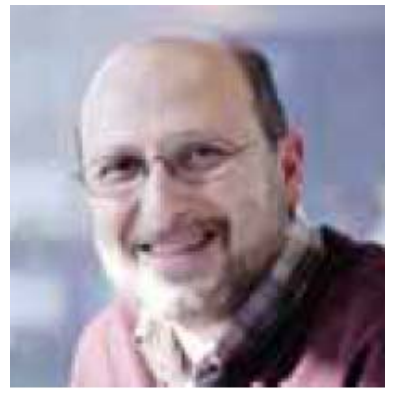

Dr. Raafat Saadé is an assistant professor at the DSMIS department, John Molson School of Business, Concordia University, Canada. Dr. Saadé obtained his Ph.D. in 1995 from Concordia University. He subsequently received the Canadian National Research Council postdoctoral fellowship, which he completed at McGill University (Montreal). He has been recognized twice as a North Atlantic Treaty Organization ASI award winner. Dr. Saadé has over 15 years of industrial experience (engineering, elearning and ehealth). He is very active in research with over 25 peer refereed journal articles. Dr. Saadé has published in top tier journals including Information \& Management, JISE, Expert Systems with Applications, Decision Sciences. Dr. Saadé is presently focusing his research on motivation in elearning and ehealth.

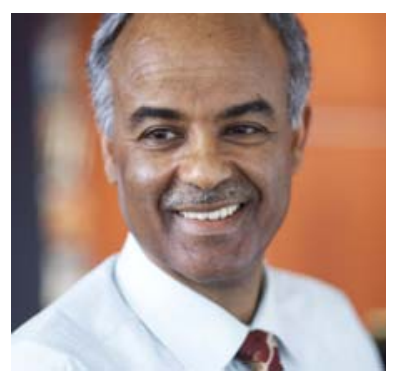

Fassil Nebebe is a Professor and Acting Chair of the Department of Decision Sciences \& M.I.S. of the John Molson School of Business, Concordia University, Montreal, Canada. His research interests are in Bayes and empirical Bayes modeling and analysis of data, resampling methods, small area estimation, statistical computing and data mining. He has served as Managing Editor of Liaison - The Newsletter of the Statistical Society of Canada and the President of the Statistical Society of Montreal. He is the founding President of the SSENA, and since 1995 he has been an International Advisory Board member of SINET: Ethiopian Journal of Science, and JESA: Journal of the Ethiopian Statistical Association.

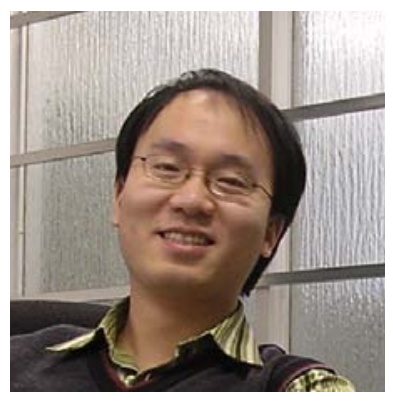

Weiwei Tan is an Ms.C. candidate at Concordia University, John Molson School of Business. His research interests are in the adoption, implementation and use of information technologies, and the business value and intelligence of Internet-based activities on individuals and organizations. Currently, Mr. Tan's thesis deals with the study of multi-media-mediated learning. 